\title{
Glutamine Randomized Studies in Early Life: The Unsolved Riddle of Experimental and Clinical Studies
}

\author{
Efrossini Briassouli ${ }^{1}$ and George Briassoulis ${ }^{2}$ \\ ${ }^{1}$ First Department of Propaedeutic Medicine, National and Kapodistrian University of Athens, Athens, Greece \\ ${ }^{2}$ Pediatric Intensive Care Unit, Division of Mother and Child, School of Medicine, University of Crete, Heraklion, Greece
}

Correspondence should be addressed to George Briassoulis, ggbriass@otenet.gr

Received 23 April 2012; Accepted 25 July 2012

Academic Editor: Rocío Martín

Copyright (C) 2012 E. Briassouli and G. Briassoulis. This is an open access article distributed under the Creative Commons Attribution License, which permits unrestricted use, distribution, and reproduction in any medium, provided the original work is properly cited.

\begin{abstract}
Glutamine may have benefits during immaturity or critical illness in early life but its effects on outcome end hardpoints are controversial. Our aim was to review randomized studies on glutamine supplementation in pups, infants, and children examining whether glutamine affects outcome. Experimental work has proposed various mechanisms of glutamine action but none of the randomized studies in early life showed any effect on mortality and only a few showed some effect on inflammatory response, organ function, and a trend for infection control. Although apparently safe in animal models (pups), premature infants, and critically ill children, glutamine supplementation does not reduce mortality or late onset sepsis, and its routine use cannot be recommended in these sensitive populations. Large prospectively stratified trials are needed to better define the crucial interrelations of "glutamineheat shock proteins-stress response" in critical illness and to identify the specific subgroups of premature neonates and critically ill infants or children who may have a greater need for glutamine and who may eventually benefit from its supplementation. The methodological problems noted in the reviewed randomized experimental and clinical trials should be seriously considered in any future well-designed large blinded randomized controlled trial involving glutamine supplementation in critical illness.
\end{abstract}

\section{Introduction}

Amino acids have a crucial role in protein synthesis, trigger signaling cascades that regulate various aspects of fuel and energy metabolism, and serve as precursors for important substrates. Glutamine, the most abundant amino acid in the muscle and plasma of humans traditionally considered a nonessential amino acid, now appears to be a conditionally essential nutrient during stress, injury [1], or illness [2]. During the acute stress of critical illness, large amounts of glutamine are produced by glutamine synthetase from muscle tissue [3] in response to stress and the regulation of glutamine synthetase protein turnover in response to glutamine concentrations [4]. Despite this significant release of glutamine, plasma levels decrease significantly following major burns in adults and remain decreased for over 21 days [5]. This severe glutamine deficiency occurs rapidly in adults and is associated with increased critical illness morbidity and mortality [6]. Similarly, the sudden cessation of glutamine supply from the mother to premature infants, who are already stressed and undergoing rapid growth, may be detrimental [7]. Thus, whereas plasma glutamine increases during the first days of life in breastfed infants [8], glutamine and arginine deficiencies have been reported in neonates suffering from acute illness [9]. In contrast to the breast milk containing glutamine adequate to influence gastrointestinal development and modulate immune, metabolic, and inflammatory responses of the newborn [10], standard infant formulas are low, and parenteral amino acid formulas are free of glutamine [11].

One described hypothesis for the release of glutamine following stress is that it provides a vital fuel source for rapidly dividing cells such as those of the immune system [12] and gastrointestinal tract [13], reticulocytes [14], and fibroblasts [15]; it is a precursor for nucleic acid synthesis, hexosamines, and nucleotides [12]; the nitric oxide precursor arginine [16]; the major antioxidant-glutathione [17]; a key precursor for acid-base homeostasis in the kidney [18]. In 
addition to its role as a gluconeogenic substrate in the intestine, liver, and kidney $[19,20]$, glutamine is involved in nitrogen transport from muscle to gut, kidney, and liver [21] and the regulation of acid-base homeostasis by renal regulation of interorgan glutamine flow in metabolic acidosis [22].

Glutamine may have benefits during experimental neonatal endotoxemia and in premature infants of very low birth weight (VLBW), who are highly stressed and have low energy and protein reserves [23]. Undergoing rapid growth, preterm infants are most likely to be exposed to severe glutamine deficiency (conditionally essential) more than term infants [7]. Glutamine supplementation may also be beneficial for critical childhood conditions including cancer, severe burns/trauma, as well as gastrointestinal disease and malnutrition. Its effects on pediatric systemic inflammation or acute illness, however, are unknown since less data is available on the effects of supplemental glutamine in infants and critically ill children. The administration of glutamine nutrient-enriched diets did not change the mortality of the critically ill or surgical adult patients, but infection complications in the critically ill patients, particularly the surgical population, were reduced [24].There is little information on the role of pharmaconutrients in neonatal endotoxemia, or whether glutamine supplementation is beneficial in preterm babies or critically ill children. The purpose of this paper was (a) to discuss the recent research-based evidence of the glutamine role in sepsis, which best of all describes a critical illness situation, and (b) to present the heterogeneity and differences of methods and results of randomized experimental and clinical studies of dietary glutamine in early life: from VLBW and preterm infants to children and up to adults.

\section{The Glutamine Role in Sepsis Immunopathology and Metabolism}

Sepsis is the systemic inflammatory response associated with an infectious insult. It is the leading cause of death in critically ill patients, and the predominant cause of multiple organ dysfunctions that is known to develop in response to infection. Sepsis occurs in over 750,000 patients per year in the United States and exhibits a mortality rate of $28 \%$ to $48 \%$ depending on the age of the patient [25]. Nosocomial infection/sepsis occurs in more than $40 \%$ of children requiring long-term intensive care [26]. Potential antiendotoxin strategies may have the potential to reduce severity of illness and length of Pediatric Intensive Care Unit (PICU) stay in critically ill children [27]. In very preterm ( $<32$ weeks of gestation) and/or very low birth weight (VLBW < $1500 \mathrm{~g}$ birth weight) infants, serious neonatal infections are among the main causes of poor developmental outcomes later in childhood. Implementation of an emergency department septic shock protocol and care guideline improved compliance in delivery of rapid, aggressive fluid resuscitation and early antibiotic and oxygen administration and was associated with decreased length of stay [28]. Despite significant advances in critical care, there is still no efficient causal therapy applicable to patients indicating the need to further elucidate the molecular pathways leading to the immunopathology of sepsis [29]. In addition, host genetic variability in the regulatory and coding regions of genes for components of the innate immune system may influence the susceptibility to and/or outcome from sepsis [30].

Specific nutrients known as pharmaconutrients have demonstrated an ability to modulate the immunologic and inflammatory responses in clinical and laboratory studies. Among these substrates, arginine, glutamine, n-3 fatty acids, and nucleotides are the most relevant and exhibit the greatest immune-modulatory action [31]. Although the mechanisms of how pharmaconutrients benefit critically ill patients have not been established, experimental work has shown that glutamine regulates the expression of many genes related to signal transduction, antioxidant capacity, immune and metabolic function [32], protein synthesis, and degradation and activates intracellular signalling pathways [33]. Thus, the effectiveness of glutamine in preventing liver damage in neonatal sepsis appears to be mediated via glutathione synthesis [34]. In addition, glutamine could improve insulin sensitivity and glucose disposal in patients suffering from critical illness, a condition frequently associated with insulin resistance and subsequent hyperglycemia [35]. By being involved in the biosynthesis of hexosamines, glutamine maintains gut wall integrity via surface mucin and glycoprotein-forming intracellular tight junctions and protects against bacterial translocation [36]. When hepatocytes from endotoxaemic rats were incubated with glutamine, there was a restoration of mitochondrial structure and metabolism. In vivo, intraperitoneal injection of glutamine into endotoxic suckling rats partially reversed hypometabolism, markedly reduced the incidence of hypothermia, and improved clinical status [37].

Activation of NF- $\kappa \mathrm{B}$ is dependent on the phosphorylation and degradation of IKB- $\alpha$, an endogenous inhibitory molecule that binds to NF- $\kappa \mathrm{B}$ in the cytoplasm [38]. In an experimental study glutamine suppressed NF- $\kappa \mathrm{B}$ transcriptional activation and translocation to the nucleus and significantly inhibited IKB- $\alpha$ phosphorylation and degradation in lung cytosolic tissue [39]. Similarly, glutamine administration attenuated the peak in IL-18 release at 12 $24 \mathrm{~h}$ and maintained IL-18 levels at a consistently low level throughout the initial 24-h period after cecal ligation and puncture (CLP) in rats [39]. Thus, glutamine's effect on IL-18 expression may be an additional mechanism by which glutamine improves survival and decreases end-organ dysfunction following polymicrobial sepsis.

\section{The Secrets of Molecular Chaperones}

The heat shock response is a highly conserved cellular mechanism that protects against injury and environmental stresses. Intracellular heat shock proteins (hsps) function as molecular chaperones governing protein assembly, folding, or transport and as anti-apoptotic regulators of cell signalling pathways leading to cell death [40]. In addition, hsp peptides promote the production of anti-inflammatory cytokines, 
indicating immune-regulatory potential of hsps [40]. Of particular importance is the expression of members of the 70-kd hsp70 family. Experimental results indicate that the expression of inducible hsp70 is vital to protect against the proinflammatory response and lung injury associated with sepsis. Induction of hsp60 has also been demonstrated in cerebral ischemia models, possibly reflecting mitochondrial stress and occurred early after the injury [41]. Sepsis, endotoxin tolerance, and heat shock all display downregulation of innate immunity, sharing a common immune suppressive effect, possibly through HS factor 1 (HSF-1)-mediated competitive inhibition of NF- $\kappa \mathrm{B}$ binding [42]. Heat shock protein 70 plasmid-transfected cells had increased hsp70 expression and demonstrated decreased nitric oxide (NO) release and inducible NO synthase messenger RNA expression in response to endotoxin compared with wild-type and empty plasmid-transfected cells [42]. Cell cycle components, regulatory proteins, and proteins in the mitogenic signal cascade may be protected by hsp70 during periods of stress [43].

Experimental evidence suggests that hsp70 expression is required for glutamine's protection against tissue injury and for attenuation of NF- $\kappa \mathrm{B}$ activation and proinflammatory cytokine release [44]. In the human gut, enteral glutamine may attenuate ubiquitin-dependent proteolysis as demonstrated by decreased ubiquitin RNA [45], and in lung and muscle, it can regulate glutamine synthetase protein degradation by facilitating its degradation by the $26 \mathrm{~S}$ proteosome [46]. It was shown that absence of hsp70 alone can significantly increase ARDS, activation of NF- $\kappa$ B, and inflammatory cytokine response whereas the specific absence of hsp70.1/3 gene expression can lead to increased mortality after septic insult [47]. The survival-promoting effects of hsp70 could also be attributed in part to the suppression of apoptosis, since reduced hsp expression in glutaminedeprived cells together with their impaired antioxidant capacity may make them more susceptible to apoptosis [48].

\section{Glutamine Is a Prochaperone}

A significant body of preexisting literature has hypothesized a relationship between hsp70 expression and glutamine's protection in both in vitro and in vivo settings [39-44]. Glutamine has been shown to induce heat shock protein expression and to attenuate lipopolysaccharide (LPS)-mediated cardiovascular dysfunction. The molecular mechanism of glutamine-induced hsp70 expression appears to be mediated via enhancement of $\mathrm{O}$-linked $\beta$-N-acetylglucosamine (OGlcNAc) modification and subsequently to increase levels of endonuclear HSF-1 expression and HSF-1 transcription activity [49]. The molecular mechanism of glutaminemediated hsp70 expression appears to be dependent on $\mathrm{O}$ GlcNAc pathway activation and subsequent O-glycosylation and phosphorylation of key transcription factors required for hsp70 induction [50]. It has been demonstrated that a single dose of intravenous glutamine enhances phosphorylation of nuclear HSF-1, which is a vital step in its transcriptional activation [51], causing a rapid and significant increase in hsp25 and hsp 72 expression in multiple organs of the unstressed Sprague-Dawley rat [52].

Pioneer studies showed that glutamine supplementation could attenuate lethal heat and oxidant injury and increase hsp72 expression in intestinal epithelial cells (IEC-6 cells) [53-55]. The effect of glutamine in delaying spontaneous apoptosis in neutrophils and protecting activated $\mathrm{T}$ cells may be mediated by upregulating glutathione [56] and Bcl2 expression and inhibiting Fas [57]. Glutamine effectively improved vascular reactivity by inducing the expression of hsp70, reducing inflammatory cytokine release and peroxide biosynthesis in LPS shock rats [58]. In a recent study, septic mice with glutamine administration showed less severe damage to the kidneys and exhibited decreased high mobility group box protein-1 (HMGB-1), toll-like receptor4 , receptor of advanced glycation end-products (RAGE), and reduced nitrotyrosine levels in kidney tissues [59]. In glutamine-treated rats, lung hsp70 and HSF-1-p expressions were enhanced, lung HMGB-1 expression and NF- $\kappa$ B DNAbinding activity were suppressed, ARDS was attenuated and survival improved [60]. Similarly, by inducing hsp70 in an experimental model, glutamine was also shown to attenuate LPS-induced cardiomyocyte damage [49].

Marked attenuation of tissue metabolic dysfunction was observed after glutamine administration as measured by lung tissue adenosine $5^{\prime}$-triphosphate/adenosine $5^{\prime}$ diphosphate ratio and the oxidized form of nicotinamide adenine dinucleotide [61]. Furthermore, the ATPase cycle of the chaperone hsp70 is regulated by co-chaperones. Hsp40 related proteins stimulate ATP hydrolysis by hsp70, whereas hsp25, which is known to be a vital protective protein via interaction with the cytoskeleton, may play an important role in glutamine's cellular protection [40]. It was shown that glutamine could protect intestinal epithelial cells in a dose-dependent fashion against heat stress and oxidant injury [53], decrease lung injury [61], and enhance hsp expression after endotoxin shock thus, improving survival [52]. It has also been shown that hsp70 levels increase in the myocardium of rats in experimental diabetes mellitus as a protective mechanism and may be further increased with parenteral administration of glutamine [62]. A randomized trial in adult patients with full-thickness burns showed for the first time that orally administered glutamine can enhance tissue hsp70 expression [63] and improve survival following lethal hyperthermia injury [64]. It was hypothesized that glutamine may act as a HSF-1 activator and increase the entire family of hsps after stress or injury since in HSF-1 knockout mouse fibroblasts, glutamine's ability to generate an hsp response is lost and the protection conferred by glutamine is also completely abrogated [51].

\section{Ornithine: A Glutamine Alternative}

Glutamine is a substrate for polyamine synthesis and stimulates the activity of ornithine decarboxylase (ODC), a key enzyme for polyamine synthesis, in intestinal epithelial cells. In a recent experimental work, polyamines (putrescine, spermidine, or spermine) and their precursor ornithine 
mediated the induction of hsp expression in IEC-18 rat intestinal epithelial cells [65]. As previously observed, glutamine was required for heat stress-induction of hsp70 and hsp25, although it had little effect under basal conditions. Under conditions of glutamine depletion, supplementation of ornithine, or polyamines restored the heat-induced expression of hsp70 and hsp25. In the same study, when ODC was inhibited by $\alpha$-difluoromethylornithine (DFMO), an irreversible ODC inhibitor, the heat stress-induction of hsp70 and hsp25 was significantly decreased even in the presence of glutamine [65]. Ornithine, polyamines, and DFMO did not modify the nuclear localization of HSF-1. However, DFMO dramatically reduced glutaminedependent HSF-1 binding to an oligonucleotide with heat shock elements (HSE) which was increased by glutamine. In addition, exogenous polyamines recovered the DNA binding activity. These results indicated that polyamines play a critical role in the glutamine-dependent induction of the intestinal epithelial heat shock response through facilitation of HSF-1 binding to HSE [65].

\section{Factors Influencing Glutamine Protective Role in Sepsis}

Recent work demonstrated that febrile-range temperatures achieved during sepsis and noninfectious SIRS correlated with detectable changes in stress gene expression in vivo (whole blood messenger RNA), thereby suggesting that fever can activate hsp70 gene expression and modify innate immune responses [66]. In addition, analysis of septic patients according to survival outcome indicated that hsp70 serum levels were modulated according to the patient oxidant status [67]. Unexpectedly, hsp70 was shown to be a key determinant of mortality in aged, but not young hosts in sepsis. It might be concluded therefore, that hsp70 may play a protective role in an age-dependent response to sepsis by preventing excessive gut apoptosis and both pulmonary and systemic inflammation [68].

Critically ill patients display variable physiologic responses when stressed; gene association studies have recently been employed to explain this variability. Genetic variants of hsp70 have also been associated with the development of septic shock in patients $[69,70]$. The specific absence of hsp70.1/3 gene expression can lead to increased mortality after septic insult [47].

Drug interactions were also shown to either suppress hsp protective effects exacerbating therefore drug-induced side effects or to induce hsp beneficial effects by suppressing drug-induced exacerbations. Thus, it was recently shown that bleomycin-induced pulmonary fibrosis is mediated by suppression of pulmonary expression of hsp70 whereas an inducer of hsp70 expression, such as geranylgeranylacetone, may be therapeutically beneficial for the treatment of gefitinib-induced pulmonary fibrosis [95].

\section{Randomized Adult Studies}

Despite the enthusiastic experimental results, suggesting a beneficial effect for the immune-enhancing glutamine, systematic reviews and meta-analyses of randomized studies failed to show any definite benefit of pharmacononutrition in the critically ill adult [96]. Most of the randomized studies have been largely performed in surgical patients [97], and only a few in trauma patients receiving glutaminesupplemented enteral nutrition [98] or septic patients on enteral immunonutrition [99].

In a multicenter, prospective, double-blind, randomized trial total parenteral nutrition (PN) supplemented with alanine-glutamine in intensive care unit patients was associated with a reduced rate of infectious complications and better glycemic control [100]. In another recent multicenter randomized, double blinded, factorial, controlled trial, 502 intensive care patients requiring $\mathrm{PN}$ were supported with parenteral glutamine $(20.2 \mathrm{~g} /$ day $)$ or selenium $(500 \mu \mathrm{g} /$ day $)$ or both, for up to seven days [101]. The primary (intention to treat) analysis showed no effect on new infections or on mortality when PN was supplemented with glutamine or selenium. Also, length of stay, days of antibiotic use, and modified SOFA score were not significantly affected by selenium or glutamine supplementation.

\section{Randomized Experimental and Clinical Studies of Glutamine Supplementation in Early Life}

The search methods for identification of studies consisted of searches of PubMed database using the search terms: "glutamine" and "critical illness," or "sepsis," or "endotoxemia." The search output was limited with the search filter for ages: pups, infants, and children. References in selected studies were examined also. The title and abstract of all studies identified by the above search strategy were screened and the full text for all potentially relevant studies published in English was obtained. The full text of any potentially relevant studies was assessed by the two authors (EB, GB). The same authors extracted data from the published studies. Study populations, main methodological data and results on outcome are presented in Tables 1, 2, and 3.

8.1. Glutamine Supplementation in Animal Pups. Using light and transmission electron microscopy in artificially reared rat pups the greatest blunting of villus height in the ileum and the lowest number of villi per unit length of bowel were in the animals that were treated with inhibition of glutamine and not provided with dietary glutamine [75]. Transmission electron microscopy demonstrated breakdown of the epithelial junctions in the glutamine-deprived and glutamine synthetase-inhibited intestines. Glutaminedeprived animals also displayed sloughing of microvilli, decreased actin cores, and degeneration of the terminal web [75]. In an experimental controlled study, glutamine and leucine both caused nutrient-induced thermogenesis in control animals and restored oxygen consumption $\left(\mathrm{VO}_{2}\right.$, $\mathrm{mL} / \mathrm{kg} / \mathrm{h}$ ) of endotoxic suckling rats [71]. Glutamine additionally increased rectal temperature, reduced incidence of hypothermia, and improved clinical signs. Undernourished pups/dam supplemented with glutamine with or without 


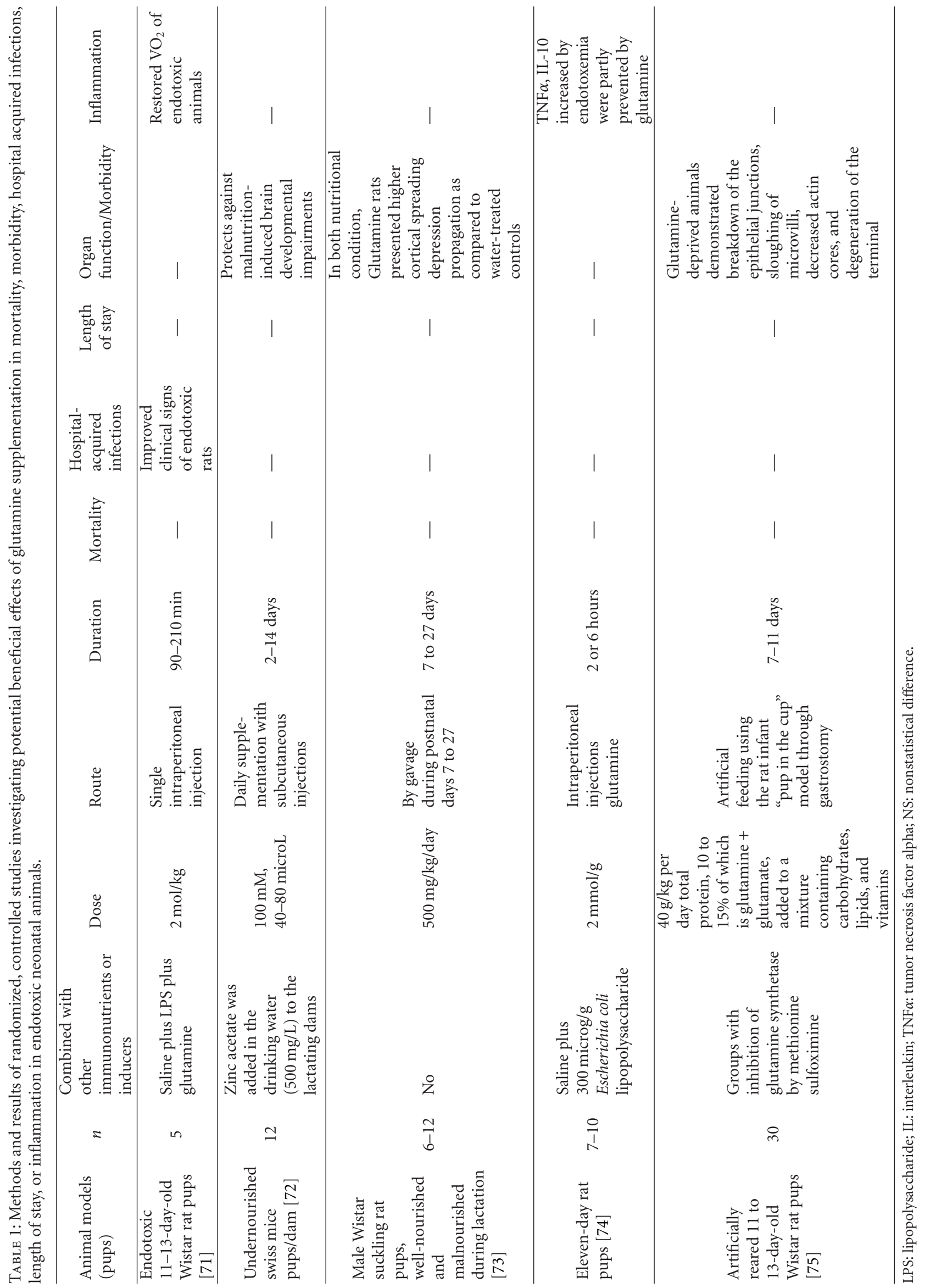




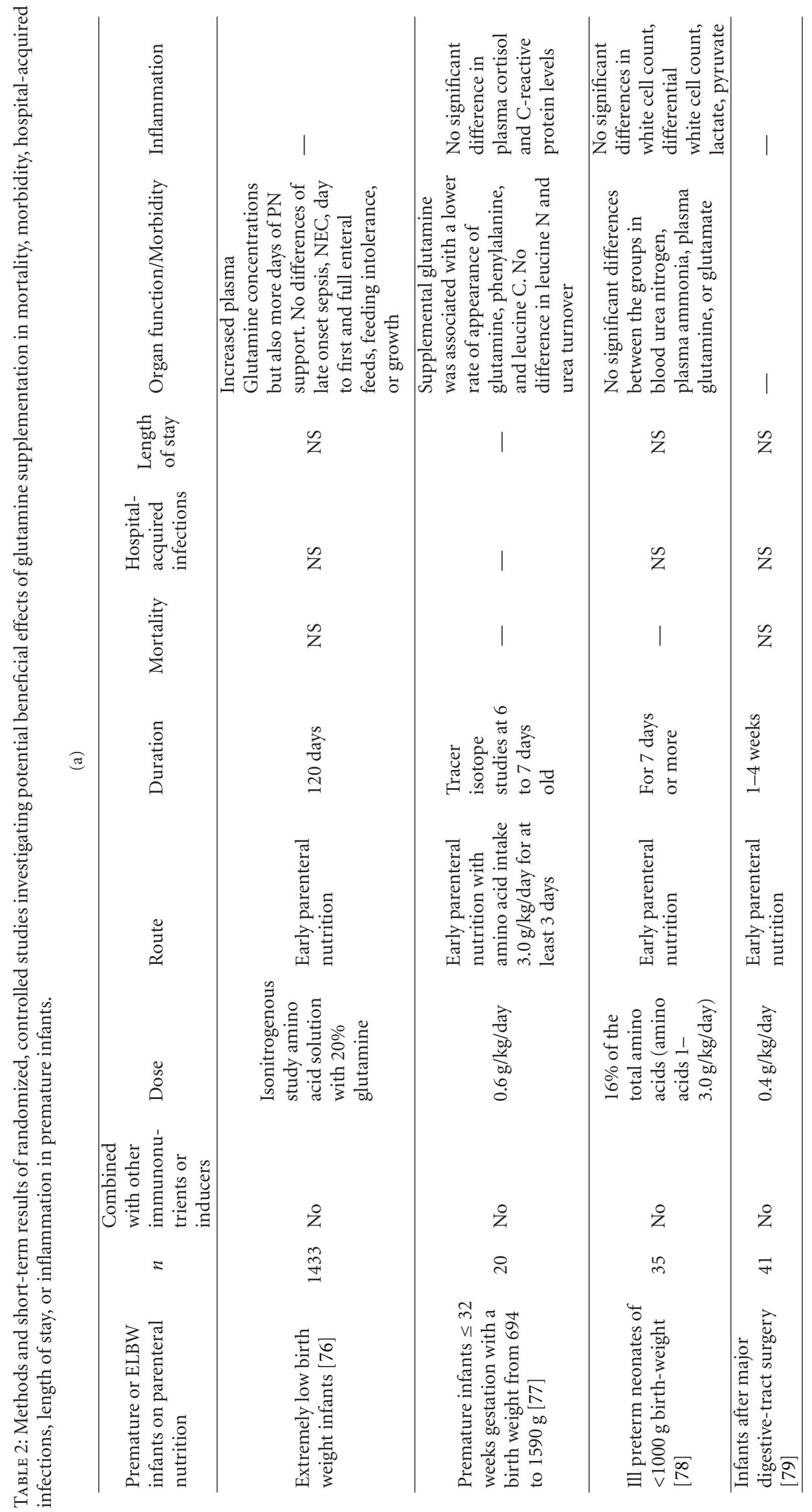




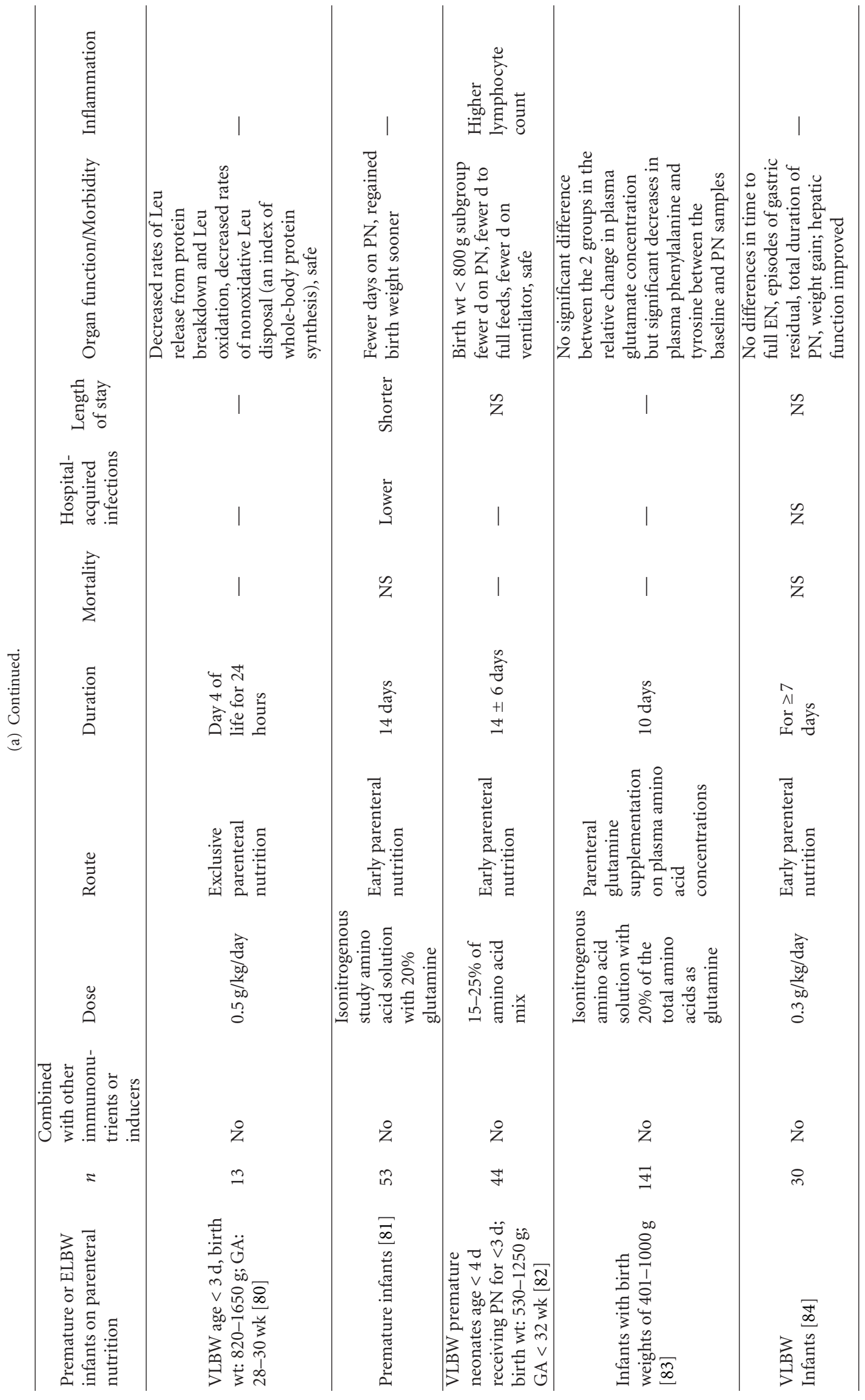




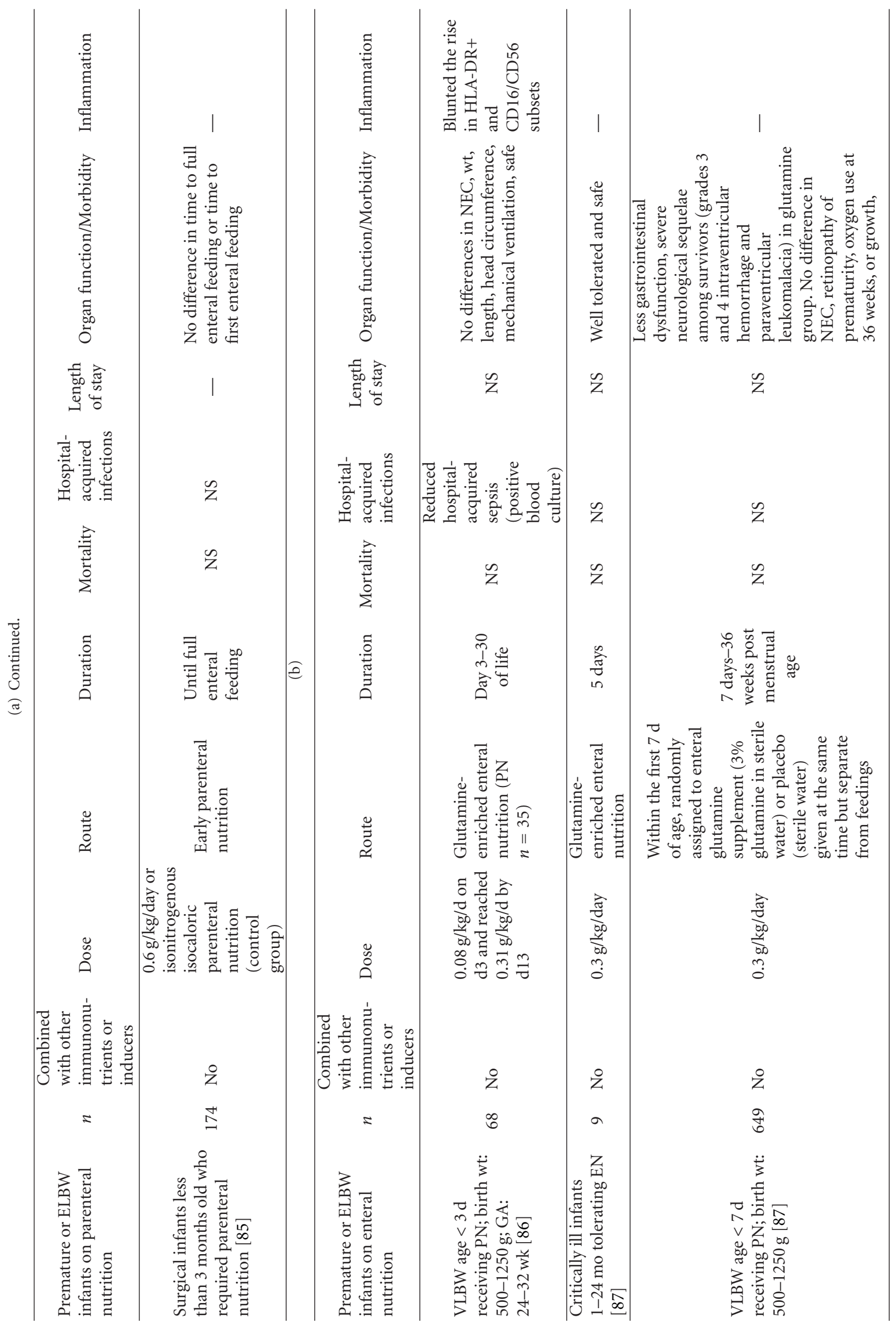




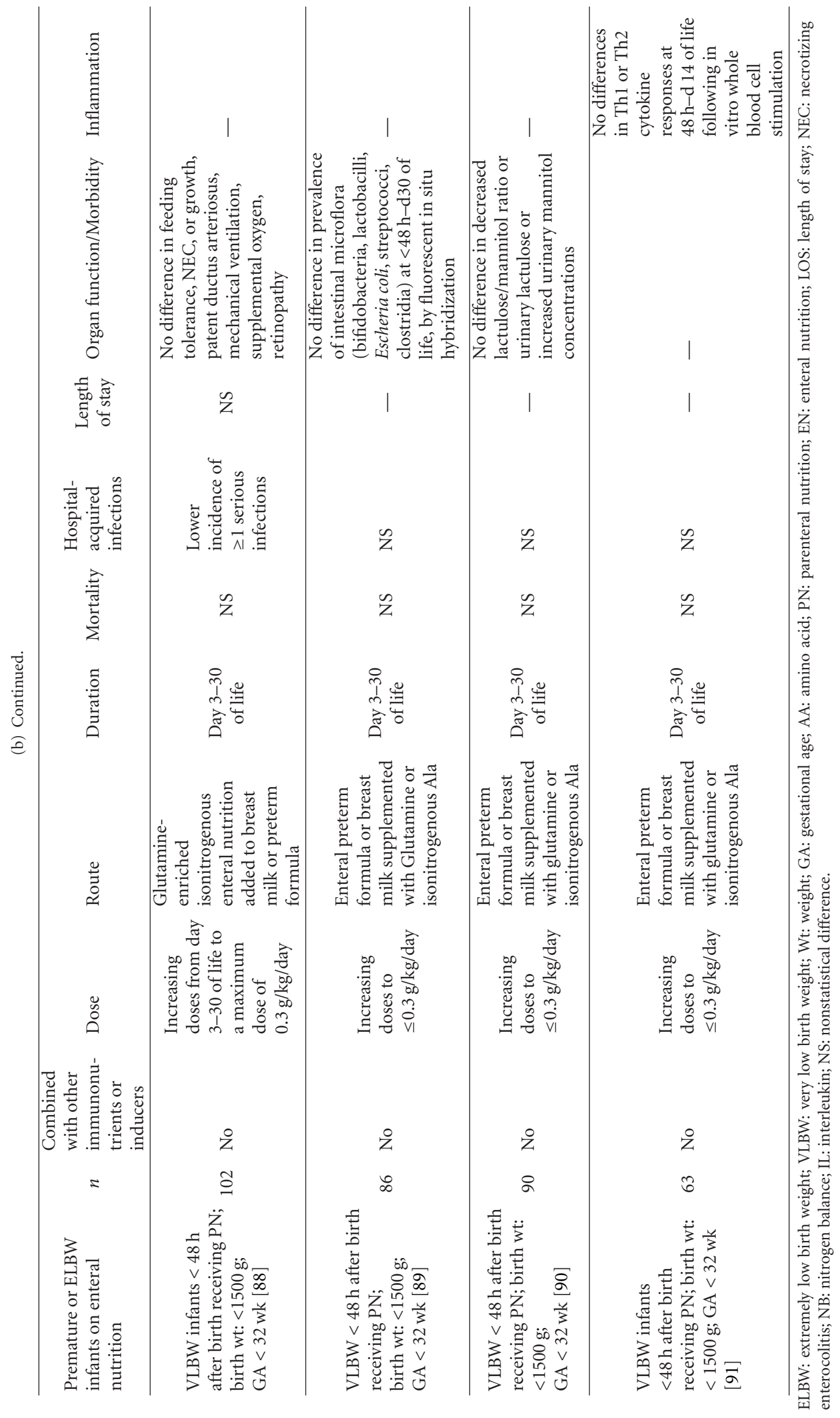




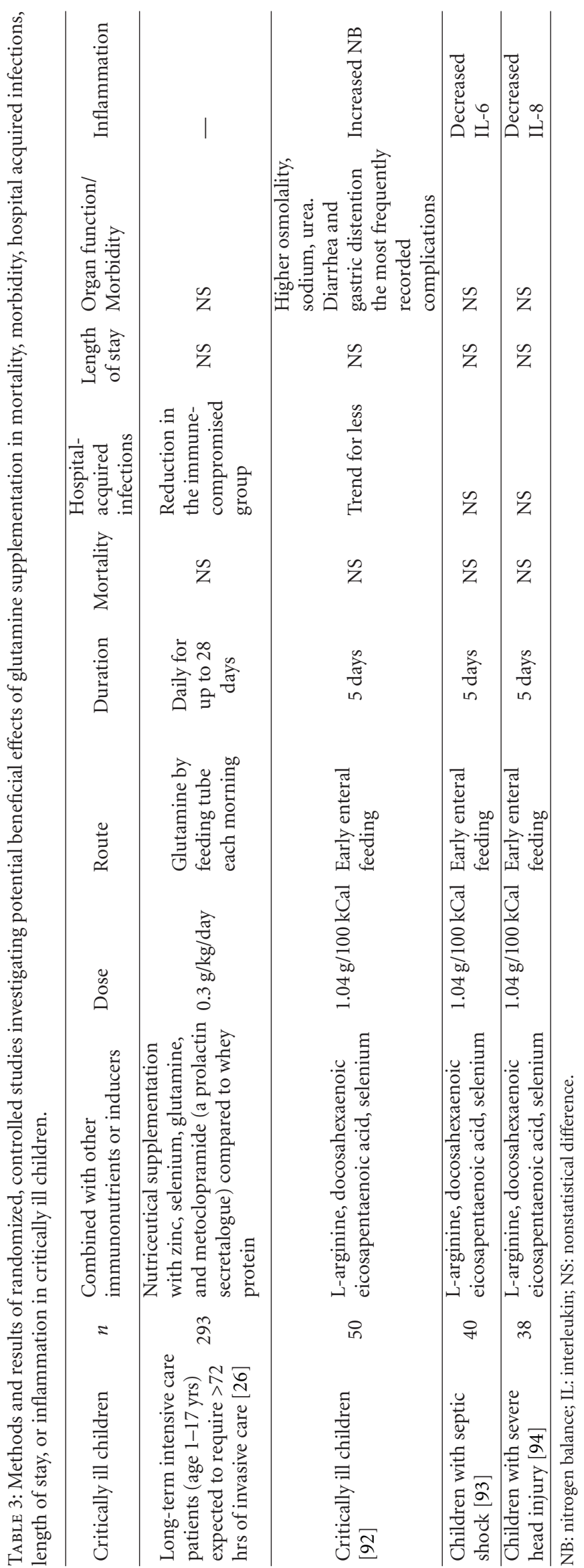


zinc showed increased CA1 layer volume and hippocampal gamma-aminobutyric acid and synaptophysin levels as compared with the other groups, consistent with the trend toward increased number of neurons and protection against malnutrition-induced brain developmental impairments [72]. Also, glutamine supplementation during brain development facilitated cortical spreading depression propagation, as judged by the higher cortical spreading depression velocities, recorded on 2 cortical parietal points of the right hemisphere, an effect not abolished by malnutrition [73]. Importantly, when injected intraperitoneally in eleven-day rat pups, glutamine partially prevented the sepsis-induced fall in plasma glutamine levels and reduced the concentration of both proinflammatory and anti-inflammatory cytokines [74].

\subsection{Parenteral Glutamine in Extremely Low Birth Weight} (ELBW) and Preterm Infants. Glutamine appears to be safe for use in premature infants and seems to be conditionally essential in premature infants with extremely low birth weights [82]. In ELBW infants, parenteral glutamine supplementation could increase plasma glutamine concentrations without apparent biochemical risk [83]. When supplemented PN for more than 2 weeks, glutamine shortened days on PN and length of stay in hospital, and decreased hospital acquired infection episodes in premature infants [81]. Although parenteral glutamine failed to enhance rates of protein synthesis, it was assumed that it may have an acute protein-sparing effect, as it suppressed leucine oxidation and protein breakdown, in parenterally fed very low birth weight infants [80]. Thus, parenteral glutamine supplementation was shown to be associated with lower whole-body protein breakdown and protein accretion in selected populations of LBW infants [77] and to improve hepatic tolerance in VLBW infants, suggesting a hepato-protective effect [84]. In another randomized study, although parenteral glutamine appeared to be well tolerated and safe in the ill preterm neonate, able to reduce the time to achieving enteral nutrition, it did not reduce the episodes of culture-positive sepsis or age at discharge [78].

In a large multicenter, randomized, double-masked, clinical trial in ELBW infants, the safety and efficacy of early PN supplemented with glutamine in decreasing the risk of death or late-onset sepsis were assessed; infants 401 to $1000 \mathrm{~g}$ were randomized within 72 hours of birth to receive either TrophAmine (control) or an isonitrogenous study amino acid solution with $20 \%$ glutamine whenever they received PN up to 120 days of age, death, or discharge from the hospital [76]. Of the 721 infants assigned to glutamine supplementation, $370(51 \%)$ died or developed late-onset sepsis, as compared with 343 of the 712 control infants $(48 \%)$. Also glutamine had no effect on tolerance of enteral feeds, necrotizing enterocolitis, or growth. No significant adverse events were observed with glutamine supplementation. Accordingly, although no harm was demonstrated, parenteral glutamine supplementation as studied in this large study could not be recommended in ELBW infants [76]. In a double-blind, randomized trial, short-term glutaminesupplementation $(0.4 \mathrm{~g} / \mathrm{kg} /$ day $)$ of $\mathrm{PN}$ did not show any benefit on intestinal permeability in newborns and infants after major digestive-tract surgery [79]. Similarly, in a recent randomized clinical trial of glutamine-supplemented versus standard PN, glutamine supplementation did not reduce the incidence of sepsis in surgical infants with gastrointestinal disease [85]. Thus, using the Cochrane Central Register of Controlled Trials (The Cochrane Library, 2011, Issue 4), MEDLINE, EMBASE and CINAHL (to November 2011), conference proceedings and previous reviews, it has been recently concluded that the available trial data do not provide evidence that glutamine supplementation confers important benefits for preterm infants [102].

\subsection{Enteral Glutamine in ELBW and Preterm Infants.} Double-blind randomized trials in VLBW infants did not show that enteral glutamine supplementation decreases morbidity or mortality $[87,103]$. Blinded, randomized studies provided evidence for a blunting of the inflammatory process [86] and lower sepsis rates in VLBW infants receiving enteral glutamine supplementation [88]. In contrast to reports showing better tolerance to enteral feedings in glutamineenriched enteral nutrition in VLBW infants [87], other studies did not find any improvement of the median days to reach full enteral feeds $[86,88]$. In addition, despite a decreased infectious morbidity, glutamine supplementation in VLBW infants was not associated with alterations in the prevalence of bifidobacteria, lactobacilli, E. coli [89] and did not enhance the postnatal decrease in intestinal permeability in this population [90]. Importantly, examining the effect of enteral glutamine on whole-body kinetics of glutamine in growing preterm infants, enterally administered glutamine was shown to be entirely metabolized in the gut and to have no detectable effect on whole-body protein and nitrogen kinetics [104]. Studied by dual tracer cross-over techniques, dietary glutamine was shown to be used to a great extent by the splanchnic tissues in preterm infants, its carbon skeleton having an important role as fuel source [105]. Similarly no differences between groups for plasma concentrations of glutamine, glutamate, other amino acids, glucose, or ammonia were shown during the enteral supplementation of glutamine [106, 107].

Followup of all surviving VLBW infants having received enteral preterm formula or breast milk supplemented with glutamine showed a lower risk of atopic dermatitis but no differences in incidence of bronchial hyperactivity, infections of upper respiratory, lower respiratory, urinary, or gastrointestinal tracts $[108,109]$, of intestinal microbiota, neurodevelopmental impairment or cerebral palsy [110]. No difference was also detected among randomized groups in intestinal (faecal) microbiota at age 1 year as analyzed by fluorescent in situ hybridization [111] or in TH1 and TH2 cytokine profiles either during the days of supplementation [91] or at 1 year of age following in vitro whole blood stimulation [112]. Importantly, glutamine-enriched enteral nutrition in VLBW infants had neither beneficial nor detrimental effects on long-term cognitive, motor, and behavioral outcomes of very preterm and/or VLBW children at school age, although visuomotor abilities were poorer in children that received glutamine [113]. 
8.4. Effect of Glutamine Supplementation on Critically Ill Children. In a multicenter randomized, double-blinded, comparative effectiveness trial, zinc, selenium, glutamine, and intravenous metoclopramide conferred no advantage in the immune-competent population of children requiring longterm intensive care compared with whey protein supplementation [26]. Further evaluation of these constituents' supplementation was thought to be warranted only in the immune-compromised long-term pediatric intensive care unit patient.

In a blinded, prospective, randomized, controlled clinical trial in critically ill children given an immune-enhancing formula supplemented with glutamine, a favorable effect on nutritional indices and antioxidant catalysts was reported, but none on outcome hard endpoints [92]. Also, although it posed a higher metabolic burden to the patient, it showed a trend to improve colonization and infection rates; diarrhea in the immunonutrition and gastric distention in the control group were the most frequently recorded complications [92]. In another single-center, randomized, blinded controlled trial in children with septic shock a significant decrease in IL-6 levels was recorded after 5 days of early enteral feeding using the same immune-enhancing formula [93]. The variation in cytokines was independently correlated only to PRISM, but mortality and other pediatric intensive care unit outcome hard endpoints did not differ between the two groups. Similarly, in another randomized, blinded, controlled study in children with severe head injury, using masked isocaloric formulae, immunonutrition improved nitrogen balance and decreased interleukin-8 and gastric colonization but was not associated with additional clinical advantage over the one demonstrated by conventional early enteral nutrition [94]. In two randomized studies in trauma patients (children and adults) no significant differences were also recorded in mortality, LOS, lung infection or immunologic or biochemical parameters between the glutamine supplemented groups (enteral or parenteral) and controls $[114,115]$.

\section{Concluding Remarks}

Given the encouraging experimental results, the absence of glutamine-related adverse effects, and the immune cells need for glutamine to grow and multiply, it has long been hypothesized that high risk patients could benefit from the use of this highly promising pharmaconutrient [12]; furthermore, combining glutamine with antioxidants and other selective pharmaconutrients, might exert an extrasynergic immune-enhancing effect. Thus, parenteral glutamine supplementation for 7 days increased total plasma glutathione levels in adult trauma patients receiving standard enteral nutrition [116]. In another study, however, glutamine administration by enteral or parenteral routes did not appear to affect antioxidant capacity or oxidative stress markers compared to unsupplemented adult ICU patients [117].

Studies evaluating the effect of specific pharmaconutrients in premature infants and critically ill children are scarce and are insufficient to allow recommendations to be made.
Recent evidence from studies in various pediatric diseases and in premature newborns remains inconsistent, partly because of the different effects of enteral and parenteral glutamine supplementation, inefficient treatment doses [118], co-administered multi-immune-enhancing constituents or more or less amino-acids, heterogeneity, timing, dosing regimens, and other [119]. In our meta-analysis, none of the randomized studies in early life showed any effect in mortality, one in the length of stay, and only a few showed some effect on inflammatory response, organ function and a trend for infection control. Thus, although apparently safe in ELBW premature infants and in critically ill children, blinded controlled randomized studies in these populations concluded that glutamine supplementation does not reduce mortality or late onset sepsis, and its routine use cannot be recommended for the immune-competent patients.

Once again, laboratory research preliminary beneficial effects failed to be reproduced in clinical randomized (and/or blinded and masked) studies. The lack of beneficial effect of glutamine supplementation in sepsis might be explained by any of the factors influencing glutamine protective role as described above. Various factors during the clinical course might have also influenced results of those studies. In addition, by using isonitrogenous controls (to ensure the specific effect of glutamine), the overall amino acid intake may have been inadequate in the glutamine group, as a consequence of the substitution of $20 \%$ of the standard amino acids with glutamine. Although adding more amino acids to the control groups might have prevented the removal of amino acids from the glutamine supplement, the isonitrogenous control groups would have then received more amino acid/nitrogen than the recommended allowances. On the other hand, enteral supplementation of glutamine seems to be locally used by the intestine but may not help entering the systemic circulation to enhance the immune response. All these different research methods along with the use of different feeding guidelines for the introduction or withholding parenteral and enteral feeds among institutions make comparisons between studies difficult [120]. Further molecular and biochemical data is needed along with large randomized controlled trials in select populations of sick children, such as immune-compromised, who may eventually benefit from supplemental glutamine.

\section{Conflict of Interests}

The authors declare that there are no conflict of interests.

\section{Acknowledgments}

This research has been cofinanced by the European Union (European Social Fund (ESF)) and Greek national funds through the Operational Program "Education and Lifelong Learning" of the National Strategic Reference Framework (NSRF)-Research Funding Program: THALES. 


\section{References}

[1] U. B. Fläring, O. E. Rooyackers, J. Wernerman, and F. Hammarqvist, "Glutamine attenuates post-traumatic glutathione depletion in human muscle," Clinical Science, vol. 104, no. 3, pp. 275-282, 2003.

[2] P. E. Wischmeyer, "Can glutamine turn off the motor that drives systemic inflammation?" Critical Care Medicine, vol. 33, no. 5, pp. 1175-1178, 2005.

[3] L. Gamrin, P. Essén, A. M. Forsberg, E. Hultman, and J. Wernerman, "A descriptive study of skeletal muscle metabolism in critically ill patients: free amino acids, energyrich phosphates, protein, nucleic acids, fat, water, and electrolytes," Critical Care Medicine, vol. 24, no. 4, pp. 575-583, 1996.

[4] B. I. Labow, W. W. Souba, and S. F. Abcouwer, "Mechanisms governing the expression of the enzymes of glutamine metabolism-glutaminase and glutamine synthetase," Journal of Nutrition, vol. 131, no. 9, pp. 2467S-2474S, 2001.

[5] M. Parry-Billings, J. Evans, P. C. Calder, and E. A. Newsholme, "Does glutamine contribute to immunosuppression after major burns?” The Lancet, vol. 336, no. 8714, pp. 523$525,1990$.

[6] P. E. Wischmeyer, "Glutamine: role in critical illness and ongoing clinical trials," Current Opinion in Gastroenterology, vol. 24, no. 2, pp. 190-197, 2008.

[7] Y. Huang, X. M. Shao, and J. Neu, "Immunonutrients and neonates," European Journal of Pediatrics, vol. 162, no. 3, pp. 122-128, 2003.

[8] F. Pohlandt, "Plasma amino acid concentrations in newborn infants breast-fed ad libitum," Journal of Pediatrics, vol. 92, no. 4, pp. 614-616, 1978.

[9] R. M. Becker, G. Wu, J. A. Galanko et al., "Reduced serum amino acid concentrations in infants with necrotizing enterocolitis," Journal of Pediatrics, vol. 137, no. 6, pp. 785793, 2000.

[10] K. M. Bernt and W. A. Walker, "Human milk as a carrier of biochemical messages," Acta Paediatrica, International Journal of Paediatrics, Supplement, vol. 88, no. 430, pp. 2741, 1999.

[11] S. Verbruggen, J. Sy, A. Arrivillaga, K. Joosten, J. Van Goudoever, and L. Castillo, "Parenteral amino acid intakes in critically Ill children: a matter of convenience," Journal of Parenteral and Enteral Nutrition, vol. 34, no. 3, pp. 329-340, 2010.

[12] E. A. Newsholme, B. Crabtree, and M. S. M. Ardawi, "Glutamine metabolism in lymphocytes: its biochemical, physiological and clinical importance," Quarterly Journal of Experimental Physiology, vol. 70, no. 4, pp. 473-489, 1985.

[13] H. G. Windmueller and A. E. Spaeth, "Respiratory fuels and nitrogen metabolism in vivo in small intestine of fed rats. Quantitative importance of glutamine, glutamate, and aspartate," Journal of Biological Chemistry, vol. 255, no. 1, pp. $107-112,1980$.

[14] S. Rapoport, J. Rost, and M. Schultze, "Glutamine and glutamate as respiratory substrates of rabbit reticulocytes," European Journal of Biochemistry, vol. 23, no. 1, pp. 166-170, 1971.

[15] D. Darmaun, D. E. Matthews, J. F. Desjeux, and D. M. Bier, "Glutamine and glutamate nitrogen exchangeable pools in cultured fibroblasts: a stable isotope study," Journal of Cellular Physiology, vol. 134, no. 1, pp. 143-148, 1988.

[16] G. C. Ligthart-Melis, M. C. G. Van De Poll, P. G. Boelens, C. H. C. Dejong, N. E. P. Deutz, and P. A. M. Van
Leeuwen, "Glutamine is an important precursor for de novo synthesis of arginine in humans," American Journal of Clinical Nutrition, vol. 87, no. 5, pp. 1282-1289, 2008.

[17] J. Neu, "Glutamine in the fetus and critically III low birth weight neonate: metabolism and mechanism of action," Journal of Nutrition, vol. 131, no. 9, pp. 2585S-2589S, 2001.

[18] D. W. Wilmore, "The effect of glutamine supplementation in patients following elective surgery and accidental injury," Journal of Nutrition, vol. 131, no. 9, pp. 2543S-2549S, 2001.

[19] N. Nurjhan, A. Bucci, G. Perriello et al., "Glutamine: a major gluconeogenic precursor and vehicle for interorgan carbon transport in man," Journal of Clinical Investigation, vol. 95, no. 1, pp. 272-277, 1995.

[20] G. Mithieux, "New data and concepts on glutamine and glucose metabolism in the gut," Current Opinion in Clinical Nutrition and Metabolic Care, vol. 4, no. 4, pp. 267-271, 2001.

[21] J. M. Lacey and D. W. Wilmore, "Is glutamine a conditionally essential amino acid?" Nutrition Reviews, vol. 48, no. 8, pp. 297-309, 1990.

[22] T. C. Welbourne, D. Childress, and G. Givens, "Renal regulation of interorgan glutamine flow in metabolic acidosis," American Journal of Physiology, vol. 251, no. 5, pp. R859R866, 1986.

[23] J. Neu, V. DeMarco, and N. Li, "Glutamine: clinical applications and mechanisms of action," Current Opinion in Clinical Nutrition \& Metabolic Care, vol. 5, no. 1, pp. 69-75, 2002.

[24] D. L. Waitzberg, H. Saito, L. D. Plank et al., "Postsurgical infections are reduced with specialized nutrition support," World Journal of Surgery, vol. 30, no. 8, pp. 1592-1604, 2006.

[25] D. C. Angus, W. T. Linde-Zwirble, J. Lidicker, G. Clermont, J. Carcillo, and M. R. Pinsky, "Epidemiology of severe sepsis in the United States: analysis of incidence, outcome, and associated costs of care," Critical Care Medicine, vol. 29, no. 7, pp. 1303-1310, 2001.

[26] J. A. Carcillo, J. M. Dean, R. Holubkov et al., "The randomized comparative pediatric critical illness stress-induced immune suppression (CRISIS) prevention trial," Pediatric Critical Care Medicine, vol. 13, no. 2, pp. 165-173, 2012.

[27] S. Dholakia, D. Inwald, H. Betts, and S. Nadel, "Endotoxemia in pediatric critical illness-a pilot study," Critical Care, vol. 15, no. 3, article R141, 2011.

[28] G. Y. Larsen, N. Mecham, and R. Greenberg, "An emergency department septic shock protocol and care guideline for children initiated at triage," Pediatrics, vol. 127, no. 6, pp. e1585-e1592, 2011.

[29] H. R. Wong, N. Z. Cvijanovich, G. L. Allen et al., "Validation of a gene expression-based subclassification strategy for pediatric septic shock," Critical Care Medicine, vol. 39, no. 11, pp. 2511-2517, 2011.

[30] M. K. Dahmer, A. Randolph, S. Vitali, and M. W. Quasney, "Genetic polymorphisms in sepsis," Pediatric Critical Care Medicine, vol. 6, supplement 3, pp. S61-S73, 2005.

[31] D. K. Heyland, F. Novak, J. W. Drover, M. Jain, X. Su, and U. Suchner, "Should immunonutrition become routine in critically III patients? A systematic review of the evidence," Journal of the American Medical Association, vol. 286, no. 8, pp. 944-953, 2001.

[32] P. E. Wischmeyer, "Glutamine: mode of action in critical illness," Critical Care Medicine, vol. 35, no. 9, pp. S541-S544, 2007.

[33] R. Curi, C. J. Lagranha, S. Q. Doi et al., "Molecular mechanisms of glutamine action," Journal of Cellular Physiology, vol. 204, no. 2, pp. 392-401, 2005. 
[34] R. Babu, S. Eaton, D. P. Drake, L. Spitz, and A. Pierro, "Glutamine and glutathione counteract the inhibitory effects of mediators of sepsis in neonatal hepatocytes," Journal of Pediatric Surgery, vol. 36, no. 2, pp. 282-286, 2001.

[35] T. Bongers, R. D. Griffiths, and A. McArdle, "Exogenous glutamine: the clinical evidence," Critical Care Medicine, vol. 35, no. 9, pp. S545-S552, 2007.

[36] N. Li, P. Lewis, D. Samuelson, K. Liboni, and J. Neu, "Glutamine regulates Caco-2 cell tight junction proteins," American Journal of Physiology, vol. 287, no. 3, pp. G726-G733, 2004.

[37] S. Eaton, "Impaired energy metabolism during neonatal sepsis: the effects of glutamine," Proceedings of the Nutrition Society, vol. 62, no. 3, pp. 745-751, 2003.

[38] B. Zingarelli, M. Sheehan, and H. R. Wong, "Nuclear factor$\kappa \mathrm{B}$ as a therapeutic target in critical care medicine," Critical Care Medicine, vol. 31, no. 1, pp. S105-S111, 2003.

[39] K. D. Singleton, V. E. Beckey, and P. E. Wischmeyer, "Glutamine prevents activation of NF- $\kappa \mathrm{B}$ and stress kinase pathways, attenuates inflammatory cytokine release, and prevents acute respiratory distress syndrome (ARDS) following sepsis," Shock, vol. 24, no. 6, pp. 583-589, 2005.

[40] T. J. Borges, L. Wieten, M. J. van Herwijnen et al., "The antiinflammatory mechanisms of Hsp70," Frontiers in Immunology, vol. 3, article 95, 2012.

[41] Y. Lai, C. Stange, S. R. Wisniewski et al., "Mitochondrial heat shock protein 60 is increased in cerebrospinal fluid following pediatric traumatic brain injury," Developmental Neuroscience, vol. 28, no. 4-5, pp. 336-341, 2006.

[42] M. Song, M. R. Pinsky, and J. A. Kellum, "Heat shock factor 1 inhibits nuclear factor- $\kappa \mathrm{B}$ nuclear binding activity during endotoxin tolerance and heat shock," Journal of Critical Care, vol. 23, no. 3, pp. 406-415, 2008.

[43] Y. G. Weiss, Z. Bromberg, N. Raj et al., "Enhanced heat shock protein 70 expression alters proteasomal degradation of $\mathrm{I} \kappa \mathrm{B}$ kinase in experimental acute respiratory distress syndrome," Critical Care Medicine, vol. 35, no. 9, pp. 2128-2138, 2007.

[44] P. E. Wischmeyer, J. Riehm, K. D. Singleton et al., "Glutamine attenuates tumor necrosis factor- $\alpha$ release and enhances heat shock protein 72 in human peripheral blood mononuclear cells," Nutrition, vol. 19, no. 1, pp. 1-6, 2003.

[45] M. Coëffier, S. Claeyssens, B. Hecketsweiler, A. Lavoinne, P. Ducrotté, and P. Déchelotte, "Enteral glutamine stimulates protein synthesis and decreases ubiquitin mRNA level in human gut mucosa," American Journal of Physiology, vol. 285, no. 2, pp. G266-G273, 2003.

[46] Y. F. Huang, Y. Wang, and M. Watford, "Glutamine directly downregulates glutamine synthetase protein levels in mouse C2C12 skeletal muscle myotubes," Journal of Nutrition, vol. 137, no. 6, pp. 1357-1362, 2007.

[47] K. D. Singleton and P. E. Wischmeyer, "Effects of HSP70.1/3 gene knockout on acute respiratory distress syndrome and the inflammatory response following sepsis," American Journal of Physiology, vol. 290, no. 5, pp. L956-L961, 2006.

[48] R. Oehler and E. Roth, "Regulative capacity of glutamine," Current Opinion in Clinical Nutrition and Metabolic Care, vol. 6, no. 3, pp. 277-282, 2003.

[49] J. Gong and L. Jing, "Glutamine induces heat shock protein 70 expression via O-GlcNAc modification and subsequent increased expression and transcriptional activity of heat shock factor-1," Minerva Anestesiologica, vol. 77, no. 5, pp. 488-495, 2011.
[50] K. D. Singleton and P. E. Wischmeyer, "Glutamine induces heat shock protein expression via O-glycosylation and phosphorylation of HSF-1 and Sp1," Journal of Parenteral and Enteral Nutrition, vol. 32, no. 4, pp. 371-376, 2008.

[51] A. L. Morrison, M. Dinges, K. D. Singleton, K. Odoms, H. R. Wong, and P. E. Wischmeyer, "Glutamine's protection against cellular injury is dependent on heat shock factor-1," American Journal of Physiology, vol. 290, no. 6, pp. C1625C1632, 2006.

[52] P. E. Wischmeyer, M. Kahana, R. Wolfson, H. Ren, M. M. Musch, and E. B. Chang, "Glutamine induces heat shock protein and protects against endotoxin shock in the rat," Journal of Applied Physiology, vol. 90, no. 6, pp. 2403-2410, 2001.

[53] P. E. Wischmeyer, M. W. Musch, M. B. Madonna, R. Thisted, and E. B. Chang, "Glutamine protects intestinal epithelial cells: role of inducible HSP70," American Journal of Physiology, vol. 272, no. 4, pp. G879-G884, 1997.

[54] M. W. Musch, D. Hayden, K. Sugi, D. Straus, and E. B. Chang, "Cell-specific induction of hsp72-mediated protection by glutamine against oxidant injury in IEC18 cells," Proceedings of the Association of American Physicians, vol. 110, no. 2, pp. 136-139, 1998.

[55] A. Chow and R. Zhang, "Glutamine reduces heat shockinduced cell death in rat intestinal epithelial cells," Journal of Nutrition, vol. 128, no. 8, pp. 1296-1301, 1998.

[56] T. C. Pithon-Curi, R. I. Schumacher, J. J. S. Freitas et al., "Glutamine delays spontaneous apoptosis in neutrophils," American Journal of Physiology, vol. 284, no. 6, pp. C1355C1361, 2003.

[57] W. K. Chang, K. D. Yang, H. Chuang, J. T. Jan, and M. F. Shaio, "Glutamine protects activated human T cells from apoptosis by up-regulating glutathione and Bcl-2 levels," Clinical Immunology, vol. 104, no. 2, pp. 151-160, 2002.

[58] L. Jing, Q. Wu, and F. Wang, "Glutamine induces heat-shock protein and protects against Escherichia coli lipopolysaccharide-induced vascular hyporeactivity in rats," Critical Care, vol. 11, article R34, 2007.

[59] Y. M. Hu, M. H. Pai, C. L. Yeh, Y. C. Hou, and S. L. Yeh, "Glutamine administration ameliorates sepsis-induced kidney injury by down regulating the high-mobility group box protein-1-mediated pathway in mice," American Journal of Physiology, vol. 302, no. 1, pp. 150-158, 2012.

[60] W. Y. Kwon, G. J. Suh, K. S. Kim et al., "Glutamine attenuates acute lung injury by inhibition of high mobility group box protein-1 expression during sepsis," British Journal of Nutrition, vol. 103, no. 6, pp. 890-898, 2010.

[61] K. D. Singleton, N. Serkova, V. E. Beckey, and P. E. Wischmeyer, "Glutamine attenuates lung injury and improves survival after sepsis: role of enhanced heat shock protein expression," Critical Care Medicine, vol. 33, no. 6, pp. 12061213, 2005.

[62] M. Ugurlucan, D. Erer, O. Karatepe et al., "Glutamine enhances the heat shock protein 70 expression as a cardioprotective mechanism in left heart tissues in the presence of diabetes mellitus," Expert Opinion on Therapeutic Targets, vol. 14, no. 11, pp. 1143-1156, 2010.

[63] P. E. Wischmeyer, J. Lynch, J. Liedel et al., "Glutamine administration reduces Gram-negative bacteremia in severely burned patients: a prospective, randomized, double-blind trial versus isonitrogenous control," Critical Care Medicine, vol. 29, no. 11, pp. 2075-2080, 2001. 
[64] K. D. Singleton and P. E. Wischmeyer, "Oral glutamine enhances heat shock protein expression and improves survival following hyperthermia," Shock, vol. 25, no. 3, pp. 295299, 2006.

[65] Y. Iwashita, T. Sakiyama, M. W. Musch, M. J. Ropeleski, H. Tsubouchi, and E. B. Chang, "Polyamines mediate glutamine-dependent induction of the intestinal epithelial heat shock response," American Journal of Physiology, vol. 301, no. 1, pp. G181-G187, 2011.

[66] L. A. Sonna, L. Hawkins, M. E. Lissauer et al., "Core temperature correlates with expression of selected stress and immunomodulatory genes in febrile patients with sepsis and noninfectious SIRS," Cell Stress \& Chaperones, vol. 15, no. 1, pp. 55-66, 2010.

[67] D. P. Gelain, M. A. De Bittencourt Pasquali, C. M. Comim et al., "Serum heat shock protein 70 levels, oxidant status, and mortality in sepsis," Shock, vol. 35, no. 5, pp. 466-470, 2011.

[68] K. W. McConnell, A. C. Fox, A. T. Clark et al., "The role of heat shock protein 70 in mediating age-dependent mortality in sepsis," Journal of Immunology, vol. 186, no. 6, pp. 37183725, 2011.

[69] C. Kee, K. Y. Cheong, K. Pham, G. W. Waterer, and S. E. L. Temple, "Genetic variation in heat shock protein 70 is associated with septic shock: narrowing the association to a specific haplotype," International Journal of Immunogenetics, vol. 35, no. 6, pp. 465-473, 2008.

[70] G. W. Waterer, L. ElBahlawan, M. W. Quasney, Q. Zhang, L. A. Kessler, and R. G. Wunderink, "Heat shock protein 70-2 + 1267 AA homozygotes have an increased risk of septic shock in adults with community-acquired pneumonia," Critical Care Medicine, vol. 31, no. 5, pp. 1367-1372, 2003.

[71] R. G. Garrett-Cox, A. Pierro, L. Spitz, and S. Eaton, "Body temperature and heat production in suckling rat endotoxaemia: beneficial effects of glutamine," Journal of Pediatric Surgery, vol. 38, no. 1, pp. 37-44, 2003.

[72] F. V. L. Ladd, A. A. B. L. Ladd, A. A. C. M. Ribeiro et al., "Zinc and glutamine improve brain development in suckling mice subjected to early postnatal malnutrition," Nutrition, vol. 26, no. 6, pp. 662-670, 2010.

[73] D. S. C. de Lima, L. M. S. de Seixas Maia, E. de Andrade Barboza, R. de Almeida Duarte, L. S. de Souza, and R. C. A. Guedes, "l-Glutamine supplementation during the lactation period facilitates cortical spreading depression in well-nourished and early-malnourished rats," Life Sciences, vol. 85, no. 5-6, pp. 241-247, 2009.

[74] R. G. Garrett-Cox, G. Stefanutti, C. Booth, N. J. Klein, A. Pierro, and S. Eaton, "Glutamine decreases inflammation in infant rat endotoxemia," Journal of Pediatric Surgery, vol. 44, no. 3, pp. 523-529, 2009.

[75] B. Potsic, N. Holliday, P. Lewis, D. Samuelson, V. DeMarco, and J. Neu, "Glutamine supplementation and deprivation: effect on artificially reared rat small intestinal morphology," Pediatric Research, vol. 52, no. 3, pp. 430-436, 2002.

[76] B. B. Poindexter, R. A. Ehrenkranz, B. J. Stoll et al., "Parenteral glutamine supplementation does not reduce the risk of mortality or late-onset sepsis in extremely low birth weight infants," Pediatrics, vol. 113, no. 5, pp. 1209-1215, 2004.

[77] S. C. Kalhan, P. S. Parimi, L. L. Gruca, and R. W. Hanson, "Glutamine supplement with parenteral nutrition decreases whole body proteolysis in low birth weight infants," Journal of Pediatrics, vol. 146, no. 5, pp. 642-647, 2005.
[78] S. W. Thompson, B. G. McClure, and T. R. J. Tubman, "A randomized, controlled trial of parenteral glutamine in ill, very low birth-weight neonates," Journal of Pediatric Gastroenterology and Nutrition, vol. 37, no. 5, pp. 550-553, 2003.

[79] M. J. I. J. Albers, E. W. Steyerberg, F. W. J. Hazebroek et al., "Glutamine supplementation of parenteral nutrition does not improve intestinal permeability, nitrogen balance, or outcome in newborns and infants undergoing digestive-tract surgery: results from a double-blind, randomized, controlled trial," Annals of Surgery, vol. 241, no. 4, pp. 599-606, 2005.

[80] C. Des Robert, O. L. Bacquer, H. Piloquet, J. C. Rozé, and D. Darmaun, "Acute effects of intravenous glutamine supplementation on protein metabolism in very low birth weight infants: a stable isotope study," Pediatric Research, vol. 51, no. 1, pp. 87-93, 2002.

[81] Z. H. Li, D. H. Wang, and M. Dong, "Effect of parenteral glutamine supplementation in premature infants," Chinese Medical Journal, vol. 120, no. 2, pp. 140-144, 2007.

[82] J. M. Lacey, J. B. Crouch, K. Benfell et al., "The effects of glutamine-supplemented parenteral nutrition in premature infants," Journal of Parenteral and Enteral Nutrition, vol. 20, no. 1, pp. 74-80, 1996.

[83] B. B. Poindexter, R. A. Ehrenkranz, B. J. Stoll, National Institute of Child Health and Human Development Neonatal Research Network et al., "Effect of parenteral glutamine supplementation on plasma amino acid concentrations in extremely low-birth-weight infants," The American Journal of Clinical Nutrition, vol. 77, no. 3, pp. 737-743, 2003.

[84] Y. Wang, Y. X. Tao, W. Cai, Q. Y. Tang, Y. Feng, and J. Wu, "Protective effect of parenteral glutamine supplementation on hepatic function in very low birth weight infants," Clinical Nutrition, vol. 29, no. 3, pp. 307-311, 2010.

[85] E. G. Ong, S. Eaton, A. M. Wade et al., "Randomized clinical trial of glutamine-supplemented versus standard parenteral nutrition in infants with surgical gastrointestinal disease," British Journal of Surgery, vol. 99, no. 7, pp. 929-938, 2012.

[86] J. Neu, J. C. Roig, W. H. Meetze et al., "Enteral glutamine supplementation for very low birth weight infants decreases morbidity," Journal of Pediatrics, vol. 131, no. 5, pp. 691-699, 1997.

[87] P. Vaughn, P. Thomas, R. Clark, and J. Neu, "Enteral glutamine supplementation and morbidity in low birth weight infants," Journal of Pediatrics, vol. 142, no. 6, pp. 662$668,2003$.

[88] A. Van Den Berg, R. M. Van Elburg, E. A. M. Westerbeek, J. W. R. Twisk, and W. P. F. Fetter, "Glutamine-enriched enteral nutrition in very-low-birth-weight infants and effects on feeding tolerance and infectious morbidity: a randomized controlled trial," American Journal of Clinical Nutrition, vol. 81, no. 6, pp. 1397-1404, 2005.

[89] A. van den Berg, R. M. van Elburg, E. A. M. Westerbeek et al., "The effect of glutamine-enriched enteral nutrition on intestinal microflora in very low birth weight infants: a randomized controlled trial," Clinical Nutrition, vol. 26, no. 4, pp. 430-439, 2007.

[90] A. Van Den Berg, W. P. F. Fetter, E. A. M. Westerbeek, I. M. Van Der Vegt, H. R. A. Van Der Molen, and R. M. Van Elburg, "The effect of glutamine-enriched enteral nutrition on intestinal permeability in very-low-birth-weight infants: a randomized controlled trial," Journal of Parenteral and Enteral Nutrition, vol. 30, no. 5, pp. 408-414, 2006. 
[91] A. Van Den Berg, R. M. Van Elburg, L. Vermeij et al., "Cytokine responses in very low birth weight infants receiving glutamine-enriched enteral nutrition," Journal of Pediatric Gastroenterology and Nutrition, vol. 48, no. 1, pp. 94 101, 2009.

[92] G. Briassoulis, O. Filippou, E. Hatzi, I. Papassotiriou, and T. Hatzis, "Early enteral administration of immunonutrition in critically ill children: results of a blinded randomized controlled clinical trial," Nutrition, vol. 21, no. 7-8, pp. 799$807,2005$.

[93] G. Briassoulis, O. Filippou, M. Kanariou, and T. Hatzis, "Comparative effects of early randomized immune or nonimmune-enhancing enteral nutrition on cytokine production in children with septic shock," Intensive Care Medicine, vol. 31, no. 6, pp. 851-858, 2005.

[94] G. Briassoulis, O. Filippou, M. Kanariou, I. Papassotiriou, and T. Hatzis, "Temporal nutritional and inflammatory changes in children with severe head injury fed a regular or an immune-enhancing diet: a randomized, controlled trial," Pediatric Critical Care Medicine, vol. 7, no. 1, pp. 56-62, 2006.

[95] T. Namba, K. Tanaka, T. Hoshino, A. Azuma, and T. Mizushima, "Suppression of expression of heat shock protein 70 by gefitinib and its contribution to pulmonary fibrosis," PLoS ONE, vol. 6, no. 11, Article ID e27296, 2011.

[96] D. K. Heyland and A. Samis, "Does immunonutrition in patients with sepsis do more harm than good?" Intensive Care Medicine, vol. 29, no. 5, pp. 669-671, 2003.

[97] J. Xu, Z. Yunshi, and R. Li, "Immunonutrition in surgical patients," Current Drug Targets, vol. 10, no. 8, pp. 771-777, 2009.

[98] A. P. J. Houdijk, E. R. Rijnsburger, J. Jansen et al., "Randomised trial of glut ami ne-enriched enterai nutrition on infectious morbidity in patients with multiple trauma," The Lancet, vol. 352, no. 9130, pp. 772-776, 1998.

[99] G. Bertolini, G. Iapichino, D. Radrizzani et al., "Early enteral immunonutrition in patients with severe sepsis: results of an interim analysis of a randomized multicentre clinical trial," Intensive Care Medicine, vol. 29, no. 5, pp. 834-840, 2003.

[100] T. Grau, A. Bonet, E. Miñambres et al., "The effect of 1alanyl-l-glutamine dipeptide supplemented total parenteral nutrition on infectious morbidity and insulin sensitivity in critically ill patients," Critical Care Medicine, vol. 39, no. 6, pp. 1263-1268, 2011.

[101] P. J. Andrews, A. Avenell, D. W. Noble et al., "Randomised trial of glutamine, selenium, or both, to supplement parenteral nutrition for critically ill patients," British Medical Journal, vol. 342, p. d1542, 2011.

[102] T. R. Tubman, S. W. Thompson, and W. McGuire, "Glutamine supplementation to prevent morbidity and mortality in preterm infants," Cochrane Database of Systematic Reviews, no. 1, Article ID CD001457, 2008.

[103] E. Barbosa, E. A. Moreira, J. E. Goes, and J. Faintuch, "Pilot study with a glutamine-supplemented enteral formula in critically ill infants," Revista do Hospital das Clínicas, vol. 54, no. 1, pp. 21-24, 1999.

[104] P. S. Parimi, S. Devapatla, L. L. Gruca, S. B. Amini, R. W. Hanson, and S. C. Kalhan, "Effect of enteral glutamine or glycine on whole-body nitrogen kinetics in very-low-birthweight infants," American Journal of Clinical Nutrition, vol. 79, no. 3, pp. 402-409, 2004.

[105] S. R. D. Van Der Schoor, H. Schierbeek, P. M. Bet et al., "Majority of dietary glutamine is utilized in first pass in preterm infants," Pediatric Research, vol. 67, no. 2, pp. 194199, 2010.
[106] J. C. Roig, W. H. Meetze, N. Auestad et al., "Enteral glutamine supplementation for the very low birthweight infant: plasma amino acid concentrations," Journal of Nutrition, vol. 126, no. 4, pp. 1115S-1120S, 1996.

[107] A. Van Den Berg, R. M. Van Elburg, T. Teerlink, H. N. Lafeber, J. W. R. Twisk, and W. P. F. Fetter, "A randomized controlled trial of enteral glutamine supplementation in very low birth weight infants: plasma amino acid concentrations," Journal of Pediatric Gastroenterology and Nutrition, vol. 41, no. 1, pp. 66-71, 2005.

[108] A. Van Den Berg, A. Van Zwol, H. A. Moll, W. P. F. Fetter, and R. M. Van Elburg, "Glutamine-enriched enteral nutrition in very low-birth-weight infants: effect on the incidence of allergic and infectious diseases in the first year of life," Archives of Pediatrics and Adolescent Medicine, vol. 161, no. 11, pp. 1095-1101, 2007.

[109] A. Van Zwol, H. A. Moll, W. P. F. Fetter, and R. M. Van Elburg, "Glutamine-enriched enteral nutrition in very low birthweight infants and allergic and infectious diseases at 6 years of age," Paediatric and Perinatal Epidemiology, vol. 25, no. 1, pp. 60-66, 2011.

[110] A. Van Zwol, A. Van Den Berg, J. Huisman et al., "Neurodevelopmental outcomes of very low-birth-weight infants after enteral glutamine supplementation in the neonatal period," Acta Paediatrica, International Journal of Paediatrics, vol. 97, no. 5, pp. 562-567, 2008.

[111] A. Van Zwol, A. Van Den Berg, J. Knol, J. W. R. Twisk, W. P. F. Fetter, and R. M. Van Elburg, "Intestinal microbiota in allergic and nonallergic 1-year-old very low birth weight infants after neonatal glutamine supplementation," Acta Paediatrica, International Journal of Paediatrics, vol. 99, no. 12, pp. 1868-1874, 2010.

[112] A. Van Zwol, A. Van Den Berg, E. E. S. Nieuwenhuis, J. W. R. Twisk, W. P. F. Fetter, and R. M. Van Elburg, "Cytokine profiles in 1-yr-old very low-birth-weight infants after enteral glutamine supplementation in the neonatal period," Pediatric Allergy and Immunology, vol. 20, no. 5, pp. 467-470, 2009.

[113] J. F. de Kieviet, J. Oosterlaan, A. van Zwol, G. Boehm, H. N. Lafeber, and R. M. van Elburg, "Effects of neonatal enteral glutamine supplementation on cognitive, motor and behavioural outcomes in very preterm and/or very low birth weight children at school age," British Journal of Nutrition, vol. 7, pp. 1-6, 2012.

[114] C. Chuntrasakul, S. Siltham, S. Sarasombath et al., "Comparison of a immunonutrition formula enriched arginine, glutamine and omega-3 fatty acid, with a currently highenriched enteral nutrition for trauma patients," Journal of the Medical Association of Thailand, vol. 86, no. 6, pp. 552-561, 2003.

[115] D. L. Yang and J. F. Xu, "Effect of dipeptide of glutamine and alanine on severe traumatic brain injury," Chinese Journal of Traumatology, vol. 10, no. 3, pp. 145-149, 2007.

[116] A. Eroglu, "The effect of intravenous alanyl-glutamine supplementation on plasma glutathione levels in intensive care unit trauma patients receiving enteral nutrition: the results of a randomized controlled trial," Anesthesia and Analgesia, vol. 109, no. 2, pp. 502-505, 2009.

[117] M. Luo, N. Bazargan, D. P. Griffith et al., "Metabolic effects of enteral versus parenteral alanyl-glutamine dipeptide administration in critically ill patients receiving enteral feeding: a pilot study," Clinical Nutrition, vol. 27, no. 2, pp. 297-306, 2008.

[118] L. Soguel, R. L. Chioléro, C. Ruffieux, and M. M. Berger, "Monitoring the clinical introduction of a glutamine and 
antioxidant solution in critically ill trauma and burn patients," Nutrition, vol. 24, no. 11-12, pp. 1123-1132, 2008.

[119] E. Mok and R. Hankard, "Glutamine supplementation in sick children: is it beneficial?" Journal of Nutrition and Metabolism, vol. 2011, Article ID 617597, 41 pages, 2011.

[120] H. E. Skillman and N. M. Mehta, "Nutrition therapy in the critically ill child," Current Opinion in Critical Care, vol. 18, no. 2, pp. 192-198, 2012. 


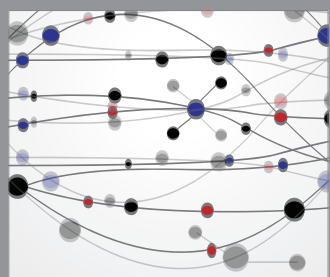

The Scientific World Journal
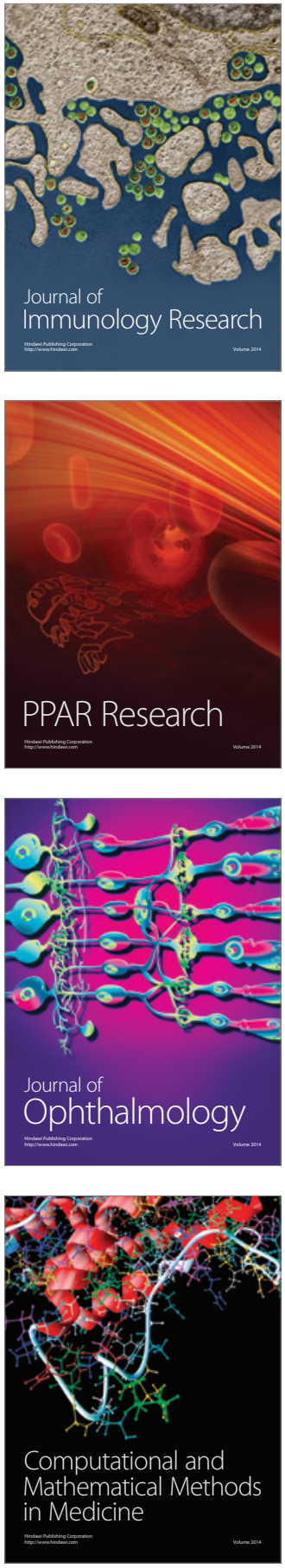

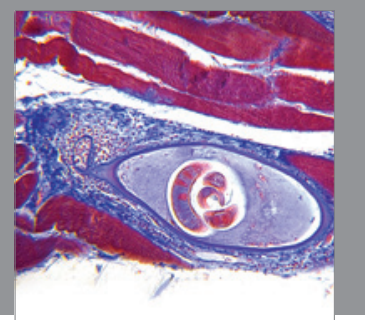

Gastroenterology

Research and Practice
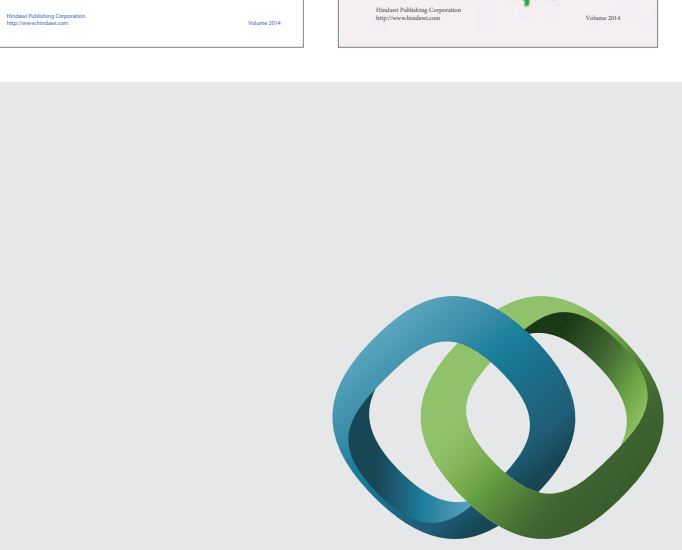

\section{Hindawi}

Submit your manuscripts at

http://www.hindawi.com


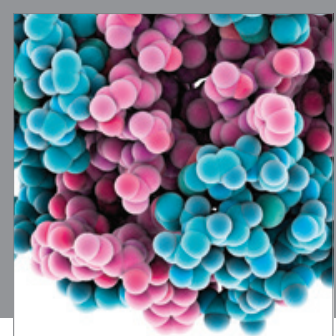

Journal of
Diabetes Research

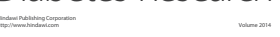

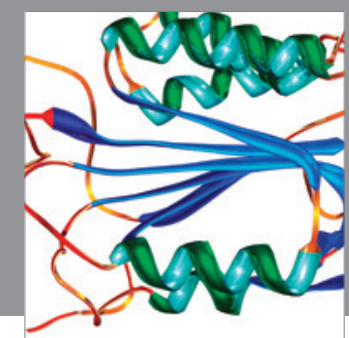

Disease Markers
